\title{
P-69
}

\section{Knowledge, Attitudes, Practices (KAP) of Complementary \& Alternative Medicine (CAM) Amongst Diploma Pharmacy Students in Malaysia}

\author{
Maryam Farooqui*, Che Noriah Othman and Mahibub Kanakal \\ Fakulty of Pharmacy, Universiti Teknologi MARA, Pulau Pinang Branch, 13200 Bertam, Pulau Pinang, Malaysia; \\ E-mail: maryam089@ppinang.uitm.edu.my
}

Introduction: Complementary and alternative medicine (CAM) is still popular and widely used throughout the world despite the presence of modern medicine. The understanding and attitude level amongst health care team including pharmacist is important to support the treatment method. The aim of this study was to investigate the level of knowledge and attitude of pharmacy students towards CAM.

Methodology: All diploma pharmacy students enrolled during 2010-2011 were invited for participations. The questionnaire was comprised of demographic characteristics, self usage, knowledge, attitude; opinion and education on CAM.

Results and discussions: There were 186 students participated in this study (70.4\%) among those 131 (\%) were CAM users. The most common types of CAM used were Traditional Malay Medicines (83.96\%). Majority of them (98\%) used CAM based on recommendation by family members, and $60.3 \%$ of them believed on the effectiveness of CAM. However there was a small percentage (4.6\%) stated that CAM is harmful to health. All CAM and non CAM users agreed that CAM is associated with health, health beliefs and values. Nearly $87 \%$ of the participants agreed that having knowledge on CAM can improve medical care. Lack of scientific evidence was among the barriers to CAM use.

Conclusions: This study concluded that students are using CAM currently as an alternative or complementary to modern medicines. It is important to include CAM education in the pharmacy curriculum as an effort to develop students with broader knowledge on CAM together with modern medicine for the betterment of pharmacy field.

Keywords: Complementary and Alternative medicine, pharmacy students, Knowledge, attitudes and practice. 